\title{
Escola pública para os negros e os pobres no Brasil: uma invenção imperial ${ }^{*}$
}

\section{Cynthia Greive Veiga}

Universidade Federal de Minas Gerais, Faculdade de Educação
Na memória da escola brasileira, a escola pública, pelo menos nos primeiros 60 anos do século XX, era tida em alta conta pela sociedade. Em geral, os grupos escolares, os ginásios, cursos de científico e Escola Normal públicos eram estabelecimentos de ensino considerados de excelência, cujas vagas eram disputadas por exames de seleção, e freqüentados por pessoas oriundas das classes média e alta. Dessa maneira, era restrito o número de pessoas das classes pobres que tinham acesso e/ou permaneciam nas escolas púbicas, pelos mais diferentes motivos, mas principalmente pela sua inserção precoce no mercado de trabalho. Também a presença de negros na escola era bastante limitada, não somente por pertencerem à camada mais pobre da população, mas também em virtude da conhecida questão das diferenças de oportunidades escolares entre brancos, pardos e negros (Hasenbalg, 1979; Gonçalves, 2000).

* Trabalho apresentado na sessão especial "História da Educação do Negro no Brasil: perspectivas e limites", durante a $30^{\mathrm{a}}$ Reunião Anual da ANPEd, realizada de 7 a 10 de outubro de 2007, em Caxambu (MG).
Contudo, na origem da implementação da escola pública elementar para todo cidadão brasileiro a partir da Constituição de 1824, na vigência da monarquia imperial, houve um crescente apelo para a necessidade de instruir e civilizar o povo. Como uma invenção imperial, em grande parte dos discursos a aprendizagem da leitura, da escrita, das contas, bem como a freqüência à escola se apresentava como fator condicional de edificação de uma nova sociedade. Mas ressalte-se o impedimento legal de frequiência dos escravos às aulas públicas em várias províncias do Império. Esse fator tem sido interpretado também como impedimento da freqüência dos negros, gerando uma série de equívocos na história da escola.

Portanto, observa-se na historiografia mais geral e na historiografia da educação em particular a permanência de um registro que invariavelmente associa os negros aos escravos e vice-versa, inclusive com ausência de ressalvas importantes, como o aumento significativo da população negra livre e a crescente diminuição da população escrava a partir de metade do século XIX (Mattos, 2006). Por isso, a sinonímia entre negros e escravos precisa ser problematizada no 
sentido de ampliarmos os estudos sobre a história do negro no Brasil e aqui avançarmos especialmente na investigação sobre os negros na história da educação e da própria história da educação brasileira.

Ao tomar negros por escravos, estudiosos acabam por limitar a discussão sobre o lugar da escola pública na organização das nações modernas e dos Estados constitucionais. Apenas para citar dois exemplos e a permanência do equívoco: em artigo de 1994, relativo à instrução de escravos e libertos, Sarita M. Affonso Moysés afirma que a Constituição de 1824 "proibia o acesso à Educação aos pretos, negros e crioulos" (Moysés, 1994, p. 200); em outro livro, em capítulo sobre a escravidão, Mario Maestri reitera: "As escolas urbanas estavam vedadas ao ingresso de negros livres, que dirá aos cativos" (Maestri, 2004, p. 205). Com todo respeito por esses pesquisadores, é preciso refletir, como veremos, sobre os motivos da sinonímia entre negros e escravos e sua longa duração histórica. ${ }^{1}$

Quanto ao acesso dos escravos à aprendizagem da leitura e da escrita, importantes pesquisas foram realizadas indicando tal prática desde o século XVIII, ainda que não necessariamente realizada numa escola. Entre outros, esse é o caso, por exemplo, dos estudos de Luiz Carlos Villalta (1999) e Eduardo França Paiva (2003), além de estudos mais recentes, como o de Christianni Cardoso Moraes (2007). Em minha própria pesquisa foi possível encontrar listas de freqüência de alunos em aulas particulares com registros de meninos escravos, como a do professor José Carlos Ferreira, de Cachoeira do Campo (província de Minas Gerais), que na sua lista de 1832 registrou Victor Máximo, 5 anos, escravo de Manoel Murta, e Antonio Manuel da Guerra, 7 anos, escravo de Manoel Guerra (IP 3/2, caixa 01 , pacotilha 33 ).

${ }^{1} \mathrm{~A}$ inquietação quanto à associação entre negro e escravo teve sua origem no contexto de realização de uma pesquisa de pósdoutoramento em 2003, com prosseguimento e aprofundamentos posteriores. Nessa pesquisa foi possível comprovar a presença de pobres, negros e mestiços na escola pública elementar do Império, e assim redimensionar o significado da função da escola em sua missão civilizadora (Veiga, 2003).
Sobre a escolarização de negros e mestiços ao longo do século XIX, poucos estudos foram realizados de maneira que dessem visibilidade a uma outra possibilidade de vida dos afrodescendentes que não associada ao mundo da escravidão ou da marginalidade. Ainda assim, observa-se em geral certo espanto dos historiadores quanto ao fato de haver negros que soubessem ler, escrever e/ou contar. Contudo, tal procedimento precisa ser mais bem problematizado, ou melhor, é preciso perguntar sobre o lugar da leitura e do letramento na sociedade imperial brasileira, levando-se em consideração três constatações muito distintas: a presença reiterada do discurso da missão civilizadora da escola por parte das elites governamentais; as precárias condições de funcionamento das escolas públicas de maneira geral; e o alto índice de analfabetismo em fins do século XIX. De acordo com Lilia Schwarcz (1998), o recenseamento de 1872 indicou que $84 \%$ da população brasileira era de analfabetos; portanto, é possível especular que também muitos brancos, inclusive abastados, não sabiam ler.

Sobre a instrução dos pobres, temos que, na historiografia, criança pobre é em geral objeto de estudo de quem investiga instituições destinadas especialmente a elas, tais como orfanatos, asilos, escolas de aprendizagem de ofícios. Assim, Mary del Priore, na introdução do livro História das crianças no Brasil, de 1999, afirma: "No século XIX, a alternativa para os filhos dos pobres não seria a educação, mas a sua transformação em cidadãos úteis e produtivos na lavoura, enquanto os filhos de uma pequena elite eram ensinados por professores particulares" (Priore, 1999, p. 10). Contudo, já por essa época havia pesquisas que demonstraram a presença de pobres na escola, como é o caso da dissertação de Alessandra Frota Martinez, Educar e instruir: a instrução popular na corte imperial (1854-1889), de 1997. Apesar de outros estudos nos anos seguintes identificarem a presença de meninos pobres nas escolas públicas, o tema é pouco problematizado na perspectiva de refletir sobre o significado dessa clientela na origem da escola pública brasileira.

Feitas tais considerações, este texto tem como objetivo demonstrar que a escola pública elementar 
do século XIX foi essencialmente destinada a crianças pobres, negras e mestiças. Como veremos adiante, em geral, crianças das famílias abastadas brancas buscavam meios próprios de educação de seus filhos, por sua vez o discurso civilizador destinava-se àqueles que na percepção das elites careciam de civilização. Diferentemente de outras instituições, a escola teve característica fundamentalmente inclusiva no objetivo de instruir e civilizar na perspectiva de produzir coesão social (Veiga, 2005), ainda que se tenha instalado em condições muito precárias e, portanto, não se tenha constituído como uma alternativa social.

Outra questão volta-se para refletirmos que a experiência da presença de filhos da população negra e mestiça nas escolas brasileiras não é decorrente da abolição da escravidão e instalação da República; é parte da história do Brasil desde fins do século XVIII e especialmente aqui desde a Independência, da instalação da monarquia constitucional e da institucionalização da escola pública para todo cidadão brasileiro. Dessa maneira, é possível também verificar que a experiência da vivência da discriminação étnica e racial nas salas de aulas possui uma significativa longevidade histórica, não é recente e vem-se acumulando há quase duzentos anos.

Assim é que podemos afirmar que a propagação da concepção da importância da escola da organização da sociedade é uma invenção imperial, associada à difusão da Constituição. Portanto, incorporar o período imperial nas análises relativas à presença de pobres, negros e mestiços na história da escola pública brasileira pode levar-nos a problematizar melhor o fracasso da escola como vetor de civilização e homogeneização cultural da população brasileira durante a Monarquia e sua recriação como escola de alunos brancos de "boa procedência" nos anos iniciais da República. Como pudemos constatar em significativa documentação, muitas foram as causas do fracasso da escola imperial, com ênfase para os limites das condições de vida de sua clientela.

Este artigo refere-se à pesquisa finalizada recentemente sobre Minas Gerais, com recorte temporal para o período de vigência da monarquia constitucional.
Está desdobrado em três itens: o primeiro discute a implementação da obrigatoriedade escolar; em seguida demonstra a presença das crianças pobres na escola; e, finalmente, apresenta o procedimento de investigação para a identificação do não-impedimento de freqüência das crianças negras e mestiças na escola pública.

\section{A escola pública como vetor de civilização}

A Constituição Imperial (de 25 de março de 1824), no artigo 179 , item 30 , outorga como garantia da inviolabilidade dos direitos civis e políticos dos cidadãos brasileiros, entre outros dispositivos, a garantia da instrução primária gratuita a todos os cidadãos. Bernardo Pereira de Vasconcelos, então deputado mineiro na Assembléia Geral do Império (1795-1850), confirmava em relato de 1828 que

Legislando sobre a instrução publica, o principal cuidado da Assembléa Geral foi sua vulgarisação o quanto fosse possível: he deste modo, que se poderão nivelar pouco mais pouco menos as faculdades moraes dos Brazileiros, e que se aniquillara essa dependencia real, que as luzes de uma classe exerciam sob a cega ignorância da totalidade: dependencia esta que tanto contribuiu para a consolidação do Septro de ferro, que por trez seculos nos oprimio. (Carta aos Senhores Eleitores da Província de Minas Geraes, REVISTA DO ARQUIVO PÚBLICO MINEIRO, 1904, p. 236) ${ }^{2}$

Quais eram os destinatários de discursos como esse? Quais brasileiros deveriam ter faculdades morais niveladas e em relação a que outro grupo? Ao longo de todo o século XIX, apelos como elevar a situação moral dos brasileiros apresentaram-se como fator importante de elaboração da nova condição de cidadãos de direitos e deveres. Logo nos anos iniciais do Brasil independente houve grande ênfase na negação do regime absolutista e no uso, por parte das elites, de associações do tipo ignorância e depen-

${ }^{2}$ Todos os documentos aqui utilizados foram pesquisados no Arquivo Público Mineiro (Belo Horizonte) e transcritos na grafia original. 
dência política (despotismo/“escravidão colonial”) e principalmente entre instrução e liberdade/civilização. Essa concepção havia sido inclusive motivo de uma atividade escolar em uma escola mineira, como é o caso do exercício de Antonio Martins da Silva, aluno da aula pública de Forquim, entre vários outros similares. Na escrita enviada ao delegado literário (os professores assim procediam para demonstrar o desempenho de seus alunos), o menino escreveu: "Amar a liberdade aborrecer a escravidão procurar o bem público e evitar o mal da Pátria he o dever do cidadão honrado. Forquim 14 maio de 1837" (PP $1 / 42$, caixa 08 , pacotilha 09 ).

Pelo ato adicional de 12 de agosto de 1834, a legislação da instrução elementar passou a ser de competência das Assembléias Provinciais. Dessa maneira, em Minas Gerais, foi por meio da lei n. 13, de 7 de abril de 1835, e do Regulamento 13, de 25 de maio de 1835 , que se estabeleceu a normalização da instrução para toda a província, incluindo a obrigatoriedade da freqüência escolar, marcando o início de um significativo conjunto de legislações para regulamentar a educação durante todo o Império: quais seriam as pessoas a que se destinava a escola pública, obrigatória e gratuita do século XIX? Pelo quadro a seguir, chama-nos a atenção a composição étnica da população brasileira, com predominância majoritária de negros e mestiços. Ressalta-se ainda que, de acordo com a historiadora Hebe Mattos, por época da abolição da escravidão, compunham a população cativa $5 \%$ da população negra do país (Mattos, 2006, p. 111).

Quadro 1: Distribuição étnica no Brasil (séculos XVI-XIX)

\begin{tabular}{|l|r|r|r|r|r|}
\hline $\begin{array}{c}\text { Etnias-cores/tempo } \\
\text { histórico } \\
\text { e porcentagem }\end{array}$ & $\begin{array}{r}1538- \\
1600\end{array}$ & $\begin{array}{r}1601- \\
1700\end{array}$ & $\begin{array}{r}1701- \\
1800\end{array}$ & $\begin{array}{r}1801- \\
1850\end{array}$ & $\begin{array}{r}1851- \\
1890\end{array}$ \\
\hline Africanos & 20 & 30 & 20 & 12 & 2 \\
\hline Negros brasileiros & - & 20 & 21 & 19 & 13 \\
\hline Mulatos & - & 10 & 19 & 34 & 42 \\
\hline Brancos brasileiros & - & 5 & 10 & 17 & 24 \\
\hline Europeus & 30 & 25 & 22 & 14 & 17 \\
\hline Índios integrados & 50 & 10 & 8 & 4 & 2 \\
\hline
\end{tabular}

Fonte: Mussa (1991, p. 163).
Em relação à província de Minas Gerais, o censo de 1872 anotava, para um total populacional de 2.039.735 habitantes, 703.952 registrados como pardos e 471.786 como pretos, somando ambos os grupos $57,6 \%$ da população total da província (Alencastro, 1997, p. 474). Isso indica uma característica bem mestiçada da população mineira, a quem cabia "civilizar" sua cor pela escola. Pesquisas recentes de história da educação vêm também confirmando a presença de crianças negras e mestiças na escola em outras províncias do país; tais estudos possibilitam ter maior clareza quanto à afirmação do médico José Ricardo Pires de Almeida, autor de um livro de história da educação, escrito em 1889. Afirma ele:

As crianças das classes razoavelmente abastadas não vão à escola pública por que seus pais têm, mais ou menos, o preconceito de cor ou porque temem e, com razão, pela moralidade de seus filhos, em contato com essa multidão de garotos cujos pais os enviam à escola apenas para se verem longe deles algumas horas. Deste modo, estas crianças aprendem melhor e mais depressa do que aqueles que freqüentam a escola pública. (Almeida, 1989, p. 90)

Contudo, foram muitas as tensões para a implantação da obrigatoriedade escolar. Os conflitos podem ser pensados num quadro de embate de representações em que esteve presente um imaginário de sociedade constituída de população rude a ser educada. O entendimento do "outro" como objeto de civilização foi enfaticamente difundido na época, acentuando-se para o Brasil as tensões presentes nas relações interétnicas. Por exemplo, o conhecido político José Bonifácio (1763-1838) registrou em 1813 seu entendimento da população brasileira como um problema para a formação de uma nação, pois “[...] amalgamação muito difícil será a liga de tanto metal heterogêneo, como brancos, mulatos, pretos livres e escravos, índios etc. em um corpo sólido político" (Andrada e Silva, 1998, p. 170).

A escolarização do povo apresentou-se como uma condição de homogeneização cultural; a institucionalização das aulas/cadeiras de instrução pública 
elementar não teve como alvo os filhos da elite branca. Em relatório de 1862, o vice-presidente da província mineira, coronel Joaquim Camillo Teixeira da Motta, relembrava a intenção da difusão da instrução pública disposta em lei: "E entretanto seu começo foi augurado pelas mais felizes ideas, e pelos resultados que desde logo estabelecerão sensível diferença entre a nossa mais desfavorecida classe, e as de outras Províncias do Império" (Relatório, 1862, p. 18).

Na pesquisa desenvolvida foi possível detectar claramente que a clientela escolar denominada como desfavorecida pertencia à classe pobre de diferentes origens étnicas - brancos, negros e mestiços. Destacase que, em geral, houve certa homogeneização no tratamento desse grupo - pobre, negros e mestiços - como inferior, a partir de sua representação como grupo não civilizado. Como analisa Norbert Elias, a produção de um grupo social como inferior implica principalmente associar as características que o tornam assim a uma situação de anomia (Elias \& Scotson, 2000). Dessa forma, a escola passaria a ter uma função altamente relevante na sociedade.

Para o cumprimento da lei da obrigatoriedade da freqüência escolar, foram instituídos vários dispositivos, com significativa repercussão na população, isso porque diferentes motivos contribuíram para a situação geral de infreqüência dos alunos e evasão da escola, e, mesmo com a presença de regulamentações punitivas, o problema esteve longe de ser resolvido.

Um expressivo conjunto de leis prescrevia a fiscalização das escolas, principalmente das aulas públicas, seja o trabalho dos professores, seja o aproveitamento dos alunos, gerando importante documentação da instrução pública: relatórios dos visitadores, delegados literários e/ou inspetores de ensino; ofícios e correspondências diversas entre pais (ou responsáveis), professores e governo; mapas de freqüência de alunos (Veiga, 2005). É importante ressaltar que a obrigatoriedade da freqüência era para os meninos. Apesar de incentivos para a abertura de escolas de meninas, a obrigatoriedade de sua freqüência somente se deu em 1882, em virtude mesmo dos costumes de época em relação à circulação das meninas.
O regulamento da lei de 1835 normalizou uma multa a ser paga pelos pais que não fizessem seus filhos freqüentarem a aula pública, gerando as listagens de "pais omissos". De acordo com a legislação, os juízes de paz deveriam encaminhar à presidência da província a relação dos meninos que atendiam aos quesitos de obrigatoriedade de frequiência escolar (idade e condição de ser livre); tais dados eram extraídos dos mapas de população. Caso os pais não enviassem à escola os filhos aptos a frequientá-la, eram então considerados omissos.

Assim foi o procedimento do juiz de paz suplente de Arassuaí, Valensianno Luis da Cunha. Em 30 de outubro de 1839, ele encaminhou ao presidente Bernardo Jacintho da Veiga uma "Relação nominal dos pais de famílias que não têm cumprido com o artigo 12 da lei mineira $n^{\circ} 13$ em entregar seus filhos a Instrução Primária pela falta de intimações como prescreve o artigo" (Seção Provincial, códice 235). Na relação consta o nome de 84 "pais omissos", com o acréscimo das observações de que, entre 101 crianças em condições de freqüentar a escola, apenas 17 o faziam e de que havia muito mais crianças aptas a ir à escola, sendo necessário melhorar os censos.

Além da intenção de "retirar o povo da ignorância", esses procedimentos devem-se a um conjunto de fatores relacionados à própria estruturação do ensino público imperial. Por exemplo: para a existência de uma cadeira de instrução pública provida por um professor, era necessária a freqüência mínima de alunos (variando entre 20 e 25), caso contrário a cadeira era suspensa ou fechada. Como documento de comprovação de freqüência à sua aula, os professores deveriam elaborar mapas de frequiência trimestrais, comprovando tanto a existência de alunos como o cumprimento de seu próprio trabalho, pois esses mapas eram exigidos para o recebimento dos salários.

Contudo, fortes tensões apresentaram-se para a eficácia do cumprimento das normas. Em um ofício de 28 de março de 1836, o delegado literário expunha os motivos do descumprimento da lei por parte de uma mãe de família, Marta Ribeiro da Costa, de cor parda, empregada numa fazenda de Contendas: 
Mora a 6 léguas distante do Arraial, sede da aula, tem a seu cargo 2 filhas; sem outro meio de subsistência, além da lavoura, se emprega esta pobre família composta de 4 indivíduos, sendo o mais útil o filho, apesar da tenra idade. 2. Faltam todos os meios para manter aquele filho em qualquer aplicação. 3. Das razões alegadas, a suplicante pelo seu desvalimento não acha no Arraial quem o admita em casa e zele por sua pueris [...] de que é suscetível a natureza humana. Entregue o impúbere a descrição do tempo [...] as paixões, muito mais depressa se entregaria a corrupção e imoralidade que as lições ditadas pelo professor que de nada conhece fora da aula. 4. A suplicante se desencarregou da escola para aquele filho, "por causa de um só filho vem perder todos" (não tem como pagar a multa)... São estas as tristes circunstâncias da desgraçada. (Seção Provincial, IP $1 / 42$, caixa 05 , pacotilha 60 )

Essas situações de constrangimento às quais as famílias estiveram expostas associam-se também às práticas de se elaborarem as listas de "pais omissos" e sua afixação em locais públicos. Entretanto, tal posição de "ilegalidade" não foi acompanhada da criação de condições para as crianças terem freqüência regular na escola e, principalmente, aprenderem a aquilo que se esperava delas: o saber elementar escolarizado. Os motivos foram de toda ordem e de maneira combinada: pobreza da população, trabalho infantil, dispersão populacional e das escolas, inconstância na administração política, limitações pedagógicas, mas principalmente em razão da presença de uma dissonância entre a expectativa de civilizar e o imaginário de uma população concebida como grupo inferior, de “difícil educação".

\section{Crianças pobres na escola pública}

Como dito, apesar de os estudos históricos sobre crianças pobres estarem em geral relacionados a instituições de recolhimento, como roda de expostos, asilos e abrigos, para os estudos do século XIX podemos acrescentar a escola pública como um dos espaços de presença das crianças pobres e particularmente de produção da identificação "aluno pobre”. Tal denomina- ção pode ser detectada em diferentes documentos. $\mathrm{Na}$ legislação têm-se as seguintes referências: criação da caixa escolar, subsídio financeiro para professores particulares que ensinassem meninos pobres, previsão de verbas para compra de material para os alunos pobres. Nas correspondências, ofícios e mapas de freqüência de alunos, além dos relatórios de delegados ou inspetores de ensino, a alusão à pobreza é uma constante, principalmente pelos seguintes motivos: justificar a impossibilidade de cobrar multa, a falta de frequiência dos alunos e o baixo desempenho escolar.

Em contrapartida, foi possível notar na documentação que, em geral, as famílias mais abastadas não enviavam seus filhos aos mestres públicos, preferindo a aprendizagem no domicílio ou em aulas particulares. Em relatório de 1851, o vice-diretor geral da Instrução, Antonio José Ribeiro Bhering, assim afirma:

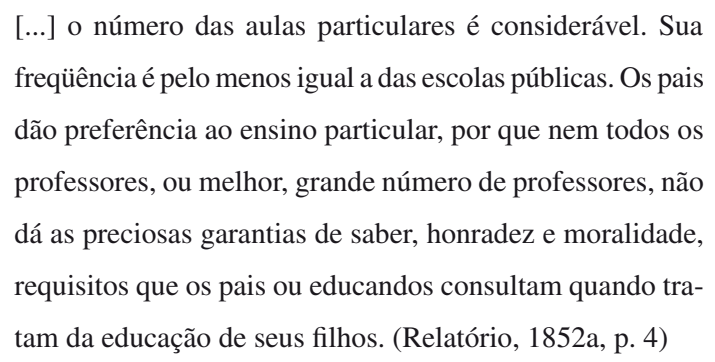

Em relatório de 1876, apresentado pelo inspetor geral da Instrução Leônidas Lessa, registra-se que na província havia uma população de 1.444 .000 pessoas, com 205.714 crianças em condições de freqüentar a escola, mas apenas 23.979 freqüentavam. Desse número foi descontado um terço de crianças que recebiam instrução doméstica. Assim, o inspetor conclui: de cada 60 crianças livres, apenas uma frequienta a aula pública; assim, um considerável número fica sem o "batismo da educação" (Relatório, 1876, anexo 4, p. 94).

A pobreza das famílias é apresentada como um elemento fundamental da infrequiência ou da frequiência irregular às aulas e, ao mesmo tempo, é um fator que inviabilizava a cobrança das multas, ocorrendo, portanto o não-cumprimento da lei. A pobreza é referida tanto pela falta de vestimentas para os meninos comparecerem à aula como pelo uso indiscriminado do 
trabalho infantil. No seu relato de 1868 , o presidente José da Costa Machado de Souza afirma:

A notavel falta de freqüência que se tem dado nas escolas d'instrução primária, o digno diretor entende, que é conseqüência da pobreza, porque os pais empregando seos filhos nos serviços à que se consagrão para poderem alimentar-se e as suas famílias, não lhe sobrando recursos para sustental-os e vestil-os nas povoações, deixão de mandal-os a escola. (Relatório, 1868, p. 21)

Não somente quase todos os relatórios fazem referência à pobreza como também várias correspondências de professores justificavam a ausência dos seus alunos em razão desse fator. Esse é o caso da professora Raymunda Franco, que, tendo sido interrogada a respeito da freqüência de seus alunos, encaminha correspondência ao inspetor em 18 de março de 1887 afirmando que "[...] os pais não estão mandando os filhos para a escola por que os meninos tem que ir para a cidade vender leite" (Seção Provincial, IP 1/1, caixa 58, p. 18).

Também o registro da pobreza pode ser verificado nos mapas elaborados por visitadores e/ou inspetores escolares e que estão anexados aos relatórios encaminhados aos presidentes de província. Assim o fez o capitão José Roiz Lages em 12 de maio de 1844 em relação a uma aula pública localizada próximo a Ouro Preto.
Observa-se que essa escola contava com a frequiência de apenas 11 alunos, bem abaixo do mínimo exigido em lei. Destaca-se que a função dos inspetores era também conferir os mapas de freqüência enviados pelos professores. Isso porque, segundo os relatos, havia muita discrepância entre o número de alunos registrados pelos professores nos mapas e o verificado pelo visitador, pois, além das adversidades presentes para os alunos freqüentarem as aulas, também o professor precisava garantir seu emprego e salário.

Entre outros documentos, há ainda ofícios de professores com listas de meninos e/ou meninas pobres necessitados de material escolar, comprovantes de despesas realizadas pelos professores com alunos pobres e os pedidos de ressarcimento, ou mesmo prestação de contas dos inspetores de materiais comprados para as escolas públicas.

\section{Crianças negras e mestiças na escola pública}

Em uma memória, o professor Anselmo Barreto, inspetor técnico do ensino de Minas Gerais, relata, sobre a escola freqüentada por ele em 1910:

Outro fato que me intrigava naquela época era a desigualdade social. Filhos de pais que exerciam profissões "mais nobres" não gostavam de relações com os colegas filhos de operários e de lavradores, muito embora existisse

Quadro 2: Escola do $1^{\circ}$ grau da Vila de S. Bárbara. Professor Nicoláo Tassara de Pádua

\begin{tabular}{|c|l|c|l|l|}
\hline Numeros & Nome dos alunnos & $\begin{array}{c}\text { Anos de } \\
\text { idade }\end{array}$ & \multicolumn{1}{|c|}{$\begin{array}{c}\text { Nome dos Paes ou } \\
\text { educadores }\end{array}$} & \multicolumn{1}{|c|}{ Observações } \\
\hline 1 & João Affonso da Cunha & 8 & F. de João Aff. da cunha & Seu pai não é pobre \\
\hline 2 & Simpliciano S. Tiago & 11 & Filho de Theotonio & Calça, camisa que denota sua pobreza \\
\hline 3 & Justiniano Ferra & 8 & Filho de Anna Antonia & Calça tinta de brauna, camisa d'algodão \\
\hline 4 & Lucas Garces & 9 & F. de Maria do Rosario & Calça, camisa de algodão \\
\hline 5 & Ponsiane Clementino & 7 & Idem Idem & Vestido só com camisa de riscado grosso \\
\hline 6 & José (Lurino) da Silva & 8 & F. de Manoel da Silva & Calça, e camisa d'algodão grosso \\
\hline 7 & João Leite & 8 & Filho de Maria Lucia & $\begin{array}{l}\text { Calça, e camisa que bem denota a pobreza } \\
\text { de sua mai }\end{array}$ \\
\hline 8 & Antonio Leite & 9 & Idem Idem & Idem \\
\hline 9 & Luis di Senna & 10 & F. de Joaquim de Senna & Calça, e camisa de droga. Hé pobre \\
\hline 10 & $\begin{array}{l}\text { Raimundo } \\
\text { Demenciano }\end{array}$ & 8 & Educador Venancio Borges & $\begin{array}{l}\text { Calça tinta de preto, camisa de algodão } \\
\text { grosso. Hé pobre. }\end{array}$ \\
\hline 11 & Francisco Dias & 8 & F. de José Dias & Calça, camisa e jaqueta de droga. Hé pobre. \\
\hline
\end{tabular}

Fonte: Presidência da Província 1/42, caixa 14, envelope 07. 
certa "aristocracia" rural. O preconceito, então, contra os pretinhos era muito grande. Ninguém gostava de ficar perto dos poucos que freqüentavam a escola. (Revista do Ensino, 1951, p. 23, grifos meus)

Embora ainda não tenhamos dados quantitativos precisos sobre a frequiência de crianças negras na escola das primeiras décadas republicanas, as mais variadas imagens sobre crianças nos grupos escolares denotam um número majoritário de crianças brancas. Em sua pesquisa, Maria Lucia Muller (1999) pergunta-se sobre a cor das professoras primárias no mesmo período e demonstra que também era bem minoritária a presença de professoras negras nas escolas, percebida, entre outras fontes, por entrevistas e iconografia.

Excetuando a pesquisa de Marcus Vinícius Fonseca (2007), pioneiro na produção de dados quantitativos sobre as cores dos alunos da escola elementar relativos à década de 30 do século XIX e à província de Minas Gerais, não temos o mesmo tipo de estudo para todo o Brasil imperial. A pesquisa desse autor demonstrou, para o período e local estudado, uma população escolar majoritariamente negra. Confirmando ou não esta tendência no período imperial para as outras décadas e para outras províncias, um problema apresenta-se: por que a escola pública brasileira, nas décadas iniciais da República e pelo menos até os anos de 1960-1970, era majoritariamente branca, quando deveria ser exatamente o contrário?

A questão aqui apresentada somente faz sentido quando identificamos a não-proibição dos negros de freqüientar a escola elementar no século XIX; dimensionamos a composição étnico-racial da população brasileira; associamos a relação entre população escrava e livre; problematizamos a constituição da República brasileira e, nela, os debates relativos à educação associados ao imaginário das condições de educação de uma sociedade mestiça. Desenvolveremos aqui apenas alguns aspectos.

Primeiramente, é importante destacar que o processo de produção dos afrodescendentes como grupo inferior na sociedade brasileira se fez por meio de práticas várias, entre elas o registro escri- to, como domínio do grupo que se autodenominou portador de atitudes civilizadas. Se tomarmos alguns grupamentos de registros, podemos observar que foi recorrente a sinonímia negros e escravos, contribuindo para uma série de equívocos na historiografia da educação brasileira por incorporar tal registro e não se dar conta da importância da diferença entre a cor e a condição jurídica das pessoas para discutir o processo de produção da inclusão escolar de crianças na recém-fundada nação. Por exemplo: como vimos, os dados gerais da população mineira indicaram a predominância de negros e mestiços livres sobre a população branca livre. Nesse caso, a sinonímia entre negro e escravo nos impossibilitaria de discutir a presença de crianças negras e mestiças na escola imperial referendando a afirmação tão recorrente de que os negros eram proibidos de freqüentar a escola, quando a proibição legal de frequiência à instrução pública se fazia aos escravos.

Minhas pesquisas têm demonstrado outra dinâmica no processo de produção da escolarização: a difusão da instrução pública elementar fez-se em direção a um público muito específico, exatamente direcionado aos filhos de uma sociedade mestiça e rude que, por ser portadora dessas características, precisaria ser escolarizada. A partir das evidências documentais, foi possível problematizar outros espaços de socialização das crianças negras e mestiças que não aqueles constituídos no reduto da escravidão.

A tradição da historiografia, de reproduzir o registro onde está presente uma identidade entre escravos e negros, vem de longa data. Embora haja poucos estudos relativos a escravos brancos, sabe-se que tal fato ocorreu, como demonstra Horácio Gutiérrez em relação ao Paraná (1988), mesmo que, pelas evidências, essa prática tenha sido bastante restrita. A escravidão dos grupos indígenas também se deu em bem menor proporção que com os africanos. Assim, os africanos constituíram o grupo preponderante de pessoas escravizadas, cuja regulação do tráfico se fez a partir de uma lógica mercantil específica. Entretanto, isso não é suficiente para refletir sobre a constante sinonímia entre negros e escravos. 
Podemos identificar outros fatores; um deles está associado à tradição historiográfica de abordagem marxista cuja ênfase caracterizou-se pela análise das relações de trabalho sem a problematização das relações interétnicas. Outro fator é analisado por Silvia Hunold Lara (1989): a influência das idéias raciais de fins do século XIX na justificativa da escravidão a partir do argumento da raça negra como raça inferior. Sem dúvida a influência das teorias raciais nos registros documentais é abundante para o final do século XIX e particularmente o para período republicano, mas também há de se destacar que os relatos de viajantes, desde o início do século XIX, faziam referência indiscriminada de negros como escravos; além do mais, tais relatos foram tomados como fonte documental por diferentes pesquisadores. Ilka Boaventura Leite (1996) afirma em sua pesquisa que tais relatos foram referência para estudiosos como Nina Rodrigues, Gilberto Freyre, Roger Bastide, Florestan Fernandes, Fernando Henrique Cardoso e Otávio Ianni, entre outros. Contudo, podemos falar de uma apropriação diferenciada, seja para confirmar a inferiorização dos negros (Nina Rodrigues), para afirmar a democracia racial (Gilberto Freyre) ou para denunciar o racismo (Bastide, Fernandes, Cardoso, Ianni).

Por sua vez, a elaboração de novas abordagens na historiografia da escravidão, a partir dos 80 do século $\mathrm{XX}$, possibilitou em parte um redimensionamento da análise do processo escravista brasileiro, embora isso não tenha significado uma nova abordagem para a história dos negros na perspectiva de relações interétnicas ou mesmo de superação do reducionismo da história dos negros a história da escravidão. Apesar de Hebe Mattos (1997) observar que são raros os registros de convivência interétnica fora da clássica relação senhor-escravo, é preciso refletir também que tradicionalmente não foram produzidas problematizações sobre essa temática, de maneira que possibilitassem outra exploração das fontes documentais.

A ausência de impedimentos para as crianças negras freqüentarem a escola imperial possibilita refletir que, no Brasil, os debates sobre civilizar pela escola, "nivelar as faculdades morais dos brasileiros", a expansão dos saberes elementares e a estatização do ensino foram perpassados por um conteúdo étnico e racial altamente significativo. A ênfase na necessidade de produção de uma homogeneização cultural significou a desqualificação das praticas culturais da população à qual se destinava a instrução pública elementar: a população de crianças negras, mestiças e pobres.

Curioso observar que, na organização da documentação sobre a instrução pública de Minas Gerais, destaca-se um importante diferencial nas escritas dos professores e/ou inspetores antes e depois da legislação provincial de 1835. Até esse ano, é possível encontrar registros da cor dos alunos e de freqüência de escravos ${ }^{3}$ não identifiquei nenhum documento posterior com tais dados. Minha interpretação é de que somente a partir da lei provincial n. 13, de 1835, é que fica realmente oficializado em Minas Gerais o impedimento de os escravos freqüentarem uma aula pública, embora não haja restrições a aulas particulares, havendo até uma lei que possibilitava tal acesso. De acordo com a lei mineira n. 1.064, de 4 de outubro de 1860 (artigo 11), tem-se que: "É livre o ensino da instrução primária em casas particulares que estiverem distante das povoações uma légua e a ela podem concorrer quaisquer pessoas de ambos os sexos, sem distinção de idade, estado, classe ou condição". ${ }^{4}$

Contudo, é menos freqüente encontrar escritas de relação de alunos de aulas particulares do que das públicas, uma vez que os professores de tais aulas não recebiam do Estado e não precisavam comprovar número de alunos. Apenas no caso de receberem subvenção por alunos pobres é que havia maior rigor na fiscalização. Ainda assim, encontramos, em 1852, registros do tipo "em todas as fazendas há mestres particulares da família. Os próprios escravos têm seus mestres. Não é raro encontrar-se nas tabernas das estradas, nas lojas de sapateiros e alfaiates 2, 3, 4 e mais meninos aprendendo a ler" (Relatório, 1852a, p. 4).

${ }^{3}$ Tais dados podem ser encontrados, por exemplo, em Seção Provincial, Instrução Pública 3/2, caixa 01, pacotilhas 05 e 17.

${ }^{4}$ Nos mapas de população o termo condição referia-se à situação jurídica, se livre ou escravo. 
Quanto ao registro da cor, ${ }^{5}$ sua presença na documentação até 1835 se fazia aleatório e de acordo com cada professor, embora bastante presente. Não havia ainda normalização para a informação dos dados de alunos. Nos mapas de frequiência encontrados, era significativa a presença de crianças negras e mestiças. É o que constata o mapa da aula de primeiras letras de quatro professores da Villa de Paracatu do Príncipe, em novembro de 1823 . Reunindo os dados tem-se: ${ }^{6}$

Quadro 3: Aulas da Vila de Paracatu do Príncipe

\begin{tabular}{|c|c|c|c|c|c|c|c|c|}
\hline $\begin{array}{c}\text { Professor/ } \\
\text { Cor dos alunos }\end{array}$ & 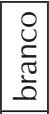 & فـ & \begin{tabular}{|l|} 
\\
$\frac{0}{0}$ \\
$\frac{0}{\pi}$ \\
2
\end{tabular} & 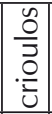 & $\frac{0}{0}$ & $\dot{2}$ & $\begin{array}{l}0 \\
\text { 이 } \\
\stackrel{0}{\complement} \\
\end{array}$ & 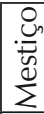 \\
\hline Domingos da Costa Braga & 08 & - & 02 & - & - & - & - & 01 \\
\hline Manoel da Ascensão Ferreira & 03 & - & 02 & - & - & - & - & - \\
\hline Manoel de Crasto Guimarães & 04 & 02 & 03 & - & - & 05 & 04 & - \\
\hline Thomas Francisco Pires & 14 & - & 14 & 04 & - & - & - & - \\
\hline Tomé Ferreira Souto & 03 & & 05 & & 01 & & & \\
\hline Total & 31 & 02 & 26 & 04 & 01 & 05 & 04 & 01 \\
\hline
\end{tabular}

Fonte: Presidência da Província 1/42, caixa 01, envelope 07.

Após 1835, as legislações regulamentam o tipo de dados a serem registrados pelos professores: nome do aluno, filiação (filho, exposto ou órfão), idade, falhas (número de faltas, acompanhadas ou não de comentários), comportamento. A ausência do item cor na documentação investigada entre 1835 e 1889 sugere a existência de uma escola pluriétnica e corrobora os pressupostos das elites, de civilizar a população “desfavorecida". Hebe Mattos, na discussão sobre tal ausência em processos-crimes a partir da segunda metade do século XIX, afirma que

[...] o crescente processo de indiferenciação entre brancos

pobres e negros e mestiços livres teria levado, por motivos opostos, à perda da cor de ambos. Não se trata necessaria-

${ }^{5}$ Não será possível discutir aqui sobre a problemática da identificação de cores no Brasil. Para estudos específicos, ver Hebe Mattos, Das cores do silêncio: os significados da liberdade no sudeste escravista, Brasil século XIX (1998), e Lilia Moritz Schwarcz, Nem preto nem branco, muito pelo contrário: cor e raça na intimidade (1998).

${ }^{6}$ Nesses registros apenas um aluno não teve a cor identificada. mente de branqueamento. Na maioria dos casos, trata-se simplesmente de silêncio. O sumiço da cor referencia-se, antes, a uma crescente absorção de negros e mestiços no mundo dos livres, que não é mais monopólio dos brancos.

(Mattos, 1998, p. 99)

Entendo que, no caso específico da institucionalização da obrigatoriedade escolar para a população livre, a ausência da cor não se fez propriamente como silêncio, mas pelo propósito claro de educar as cores pela escola, pelo acesso à instrução. Desse modo, em minha pesquisa somente foi possível identificar as cores das crianças "aptas a freqüentar a escola" no período pós-1835 pelo cruzamento de dados de mapas da população (que traz o item cor) e as listas de meninos em idade de freqüentar a escola elaborada pelos juízes de paz. Evidentemente ambos os documentos são de uma mesma localidade e de mesmo ano. Podemos demonstrar, por exemplo, no Mapa dos habitantes livres do arraial de Santo Antônio da Casa Branca e de um quarto de légua em roda, o fogo (grupo domiciliar) de número 66; Ana Maria era a chefe do fogo:

Quadro 4: Fogo de Ana Maria

\begin{tabular}{|c|c|c|c|c|c|c|c|}
\hline $\begin{array}{l}\text { № de } \\
\text { Fogos }\end{array}$ & $\begin{array}{c}\text { № de } \\
\text { habitantes }\end{array}$ & \multicolumn{2}{|c|}{ Nomes e idades } & \multirow{2}{*}{ 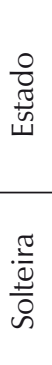 } & \multirow{2}{*}{$\begin{array}{l}\frac{0}{0} \\
\frac{\pi}{0} \\
\frac{\pi}{2} \\
\frac{\sigma}{\sigma} \\
\frac{\pi}{2} \\
\frac{0}{\tilde{U}}\end{array}$} & \multirow{2}{*}{ 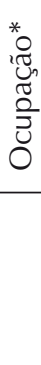 } & \multirow{2}{*}{ 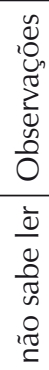 } \\
\hline \multirow{6}{*}{66} & 338 & Ana Maria & 50 & & & & \\
\hline & 339 & \begin{tabular}{l|l|} 
Maria & Filhos \\
\end{tabular} & 20 & $"$ & $"$ & & $"$ \\
\hline & 340 & Thomasia & 16 & $"$ & $"$ & & $"$ \\
\hline & 341 & Sabina & 12 & $"$ & $"$ & & $"$ \\
\hline & 342 & Francisco & 07 & $"$ & $"$ & & $"$ \\
\hline & 343 & Antonio & 05 & $"$ & $"$ & & $" 1$ \\
\hline
\end{tabular}

* Não registrado. Fonte: Seção Provincial, códice 233.

No documento Lista de meninos que há possibilidade de frequentarem huma Escola Pública de Instrução primária no Arraial de Casa Branca estão relacionados, entre vários outros, os meninos crioulos filhos da Ana Maria em idade de ir a escola.

É importante reafirmar para o período pós-1835 que somente foi possível identificar as cores das 
Quadro 5: Filhos de Ana Maria aptos a freqüentar a escola

\begin{tabular}{|c|c|c|c|}
\hline$N^{\text {os }}$ & \multicolumn{2}{|c|}{ Nomes e idades dos alunos } & Pais ou educadores \\
\hline 95 & Francisco & 07 & Ana Maria \\
\hline 96 & Antonio & 05 & " \\
\hline
\end{tabular}

Fonte: Seção Provincial, códice 233.

crianças em virtude do fato de ter sido encontrado o mapa da população, pois na documentação específica da instrução pública investigada o quesito cor não está presente. Ou seja, a princípio as cores das crianças não se apresentaram como um problema de exclusão social; inversamente, foi um problema de inclusão a ser resolvido pela escola em sua função civilizadora.

Um dado importante refere-se também às cores dos professores. Diferentes registros demonstram a presença de professores pardos e negros, além de pobres, principalmente nos relatórios de inspetores. É o caso da afirmação de Manoel Custódio Netto sobre a situação do ensino na Villa de Lavras em 1832. Segundo o relato, o mestre Joaquim da Silva era "negro, cortez e religioso, porém atrazado e excessivamente severo" (Vida Escolar, 1908, p. 3). Outra documentação é a certidão de batismo, obrigatória para prestar exames nas Escolas Normais e depois atuar na docência; como há nela o registro da cor de possíveis professores, identificam-se também pessoas negras. Destaca-se também que, logo nos anos iniciais da República, ainda se encontravam professores negros dos tempos imperiais; o inspetor Domiciano Rodrigues Vieira registra em 1899 que o professor da Escola do Pastinho (duas léguas de Belo Horizonte) era um "preto humilde, atencioso, delicado, bom homem, estimado (bom cabo eleitoral, muito jeitoso), de regular habilitação, ensina bem, é professor efetivo há mais de 20 anos" (Correspondência, 1899).

\section{Considerações finais}

Para finalizar, destaco algumas questões de reflexão sobre instrução pública no Brasil do século XIX. Apesar de a escola elementar pública apresentar-se como instituição de característica essencialmente popular, quais foram os limites de sua efetivação jun- to à população livre? Nos documentos investigados, observa-se uma imensa dissonância entre os discursos e as ações efetivas para consolidar a instrução.

Entre os muitos motivos podem-se destacar basicamente quatro: a estrutura política do período imperial; o contexto material das escolas; as condições de frequiência à aula e a situação dos professores. Sobre o primeiro, percebe-se que, de maneira geral, as elites se mostraram empenhadas na difusão da instrução - manifestavam proposições integradas ao discurso ocidental do lugar da instrução para a civilização, tinham previsão de gastos para a educação e elaboravam de maneira crítica seus registros sobre a precariedade do estado geral da instrução. Entretanto, a estrutura política e as redes de interdependência (Elias, 1993) tecidas pelas próprias elites contribuíam muitíssimo pouco para a efetivação e o avanço de qualquer proposição.

Os assuntos da instrução eram centralizados na figura do presidente da província. No caso de Minas Gerais, como medida administrativa adotou-se a divisão da província em círculos literários (1835) e, para efetivação da fiscalização do ensino, a criação de órgãos como a Diretoria Geral da Instrução Pública (1848) e a Inspetoria Geral da Instrução (1872); isso, contudo, não favoreceu a autonomia dos administradores. Por sua vez, a administração imperial foi caracterizada pela alta rotatividade na ocupação de cargos, seja de presidente ou de outros cargos, fato característico da cultura política imperial do clientelismo.

Acrescem-se a isso questões como vastidão do território, rarefação da população e precária infra-estrutura (de estradas e transportes) e, conseqüentemente, dificuldades na abertura de escolas e fiscalização de seu funcionamento. Em 1881, um inspetor registrou em seu relatório que a província possuía apenas uma escola pública para 328 crianças; dessas, somente 23 freqüentavam as aulas, sendo que 21 nada aprendiam e, portanto apenas duas estavam prontas (Relatório, 1881, p. 52). Em 1882, outro inspetor atestava que Minas Gerais possuía $75 \%$ de população analfabeta (Relatório, 1882, p. 8).

Um segundo problema era que, apesar de os governos disponibilizarem verbas para a instrução 
pública, as condições de funcionamento das escolas eram muito precárias. Destaca-se a falta de prédios próprios (grande parcela das aulas acontecia na casa do professor) e de material escolar (pela documentação, havia dificuldade de se fazer chegar às casas, entraves na sua aquisição, o pedido do professor não era atendido ou ainda extravios).

Numa terceira ordem de considerações, tem-se que as condições de frequiência à escola eram rodeadas de muitos problemas; desde questões mais práticas, como dificuldade de locomoção até a aula do professor (chuva, alagados, matas, caminhos não seguros), até as mais conflituosas relações ocorridas entre o Estado e as famílias. Estas não enviavam seus filhos às escolas por diferentes motivos: pobreza (falta de roupa adequada, trabalho, fome); indiferença quanto à importância da instrução; dificuldades com o professor e seu método. No relato de 1867 do diretor-geral da Instrução Pública, Firmino Antonio de Sousa, ele afirma:

Já se vê, pois, que a instrucção bebida nas escolas primarias quasi que de nenhuma utilidade é na prática da vida, e talvez seja este o principal motivo que as classes inferiores de nossa sociedade olhão com tanta indiferença para a educação literaria que o estado gratuitamente lhes offerece, e cujas vantagens práticas elas ainda não conseguirão descobrir. (Relatório, 1867, p. 2)

Contudo, ao mesmo tempo podemos encontrar vários abaixo-assinados de pais pedindo a abertura de aulas públicas, seja do sexo feminino ou masculino, sendo um procedimento inclusive previsto em lei (Veiga, 2002). As dificuldades com os professores vêm de relação pessoal, em casos como violência física (castigo, abuso da palmatória, estupro), de embriaguez ou mesmo das limitações dos métodos pedagógicos, pela demora na aprendizagem da leitura, escrita e contas. Em 1873, o inspetor Antonio de Assis Martins relata:

[...] entre nós, geralmente fallando, o menino matricula-se na escola na idade de cinco para seis annos e aos doze mal sabe soletrar, e quando é feliz, assigna com bastante desi- gualdade seu próprio nome. Seis annos de aprendizagem para tão mesquinho resultado forçosamente deve desanimar, principalmente a essa classe pobre, que vê no filho mais um recurso, de que póde dispor, para ajudal-o a carregar o peso de uma vida, toda cheia de fadigas e necessidades. (Relatório, 1873, p. 8)

Assim, o quarto problema da insuficiência do ensino diz respeito aos professores. Do ponto de vista da legislação, a regulamentação do magistério é a mais abundante de todas. Houve uma clara opção política em regulamentar o emprego público do professor em detrimento de sua formação. De um lado, proliferavam-se arranjos para a manutenção do cargo por meio de disputas e querelas políticas locais; de outro, tem-se grande precariedade e irregularidade de funcionamento das escolas normais. Acresce-se ainda que, no caso de Minas Gerais, até 1872 o currículo não ultrapassava o estudo de método de ensino e as próprias disciplinas da instrução elementar. Embora os relatores sejam quase unânimes em afirmar ser esse um dos principais problemas da instrução, mesmo com as alterações produzidas os dados continuavam a revelar uma aprendizagem rotineira e limitada, fundada principalmente na memorização. Havia ainda problemas relativos a baixos salários, pagamento irregular e desinteresse pela profissão.

Ainda assim, os discursos dos gestores enfatizavam a educação popular como condição de progresso e civilização. No relatório de 1875, o vice-presidente Francisco Leite da Costa Belém falava do empenho em generalizar a instrução, de modo a "patentear a todo cidadão, ainda ao de mais humilde e obscura procedência" (Relatório, 1875). Contudo, ao que tudo indica, "os humildes e de obscura procedência" não tiveram condições de permanência em uma instrução regular.

[...] devo, entretanto conffessar que a indole de nossas crianças, máxime em vista da educação doméstica que recebem; a falta de limitação de edade para a frequiência das escolas confiadas a tal direcção, e o fato de serem os alumnos que a frequientam de todas as procedências, o que é, sem dú- 
vida um elemento poderoso de desordem e perturbação da indispensável disciplina escolar, constituem embaraço sério a realização d'esse systema de direção, capaz de fructificar proveitosamente só nas escolas freqüentadas por crianças, escolhidas em vista da edade ou dos precedentes de família. (Falla, 1882, p. 9, grifos meus)

Observa-se, assim, que os mecanismos internos e cotidianos de exclusão há muito estiveram presentes na história da escola brasileira. Portanto, às questões aqui identificadas para explicar a precariedade da escola pública elementar do século XIX deve-se acrescentar principalmente o problema da clientela escolar, suas cores e pobreza, em que a chamada má procedência se apresentava como impedimento social. Pode-se dizer que a escola imperial fracassou na sua missão de "educar as procedências".

Dessa maneira, ao ser anunciada a República, já se tinha um considerável acúmulo de experiências relativas aos processos de discriminação e preconceitos também no ambiente escolar. Isso ensejou a busca de técnicas voltadas à depuração dos alunos de "todas as procedências”, a partir da elaboração de testes escolares e da instituição da escola seriada (grupos escolares) como práticas científicas de organização escolar. Para a escola pública deixar de ser indigente, foi necessário que também a sua clientela fosse outra - crianças de famílias de "boa procedência" -; pelo menos é o que

\section{Figura 1}

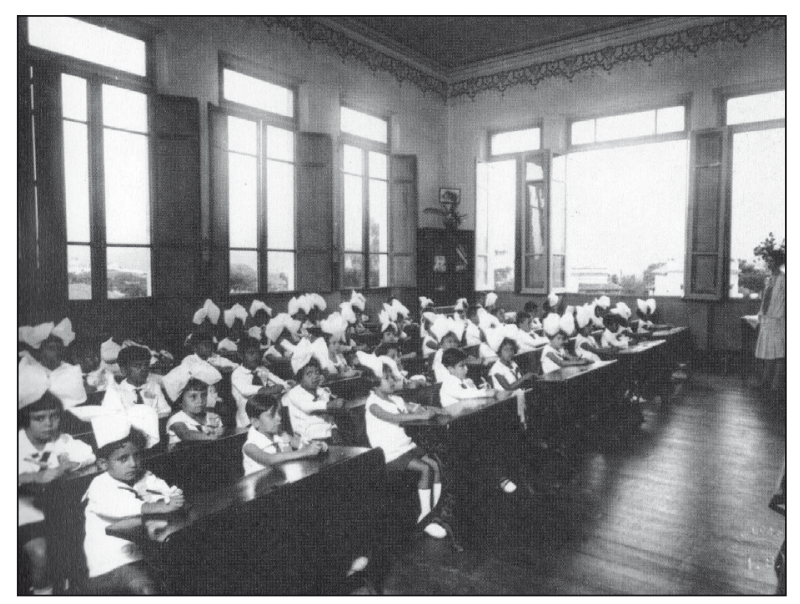

Fonte: Acervo do Centro de Referência do Professor. Belo Horizonte (MG). podemos verificar, em geral, nos alunos das escolas públicas brasileiras, principalmente das principais capitais, até por volta da década de 60 do século XX. É o que podemos conferir, entre outras possibilidades de fontes, na imagem a seguir, de uma sala de aula de um grupo escolar de Belo Horizonte na década de 20 do século XX.

\section{Referências bibliográficas}

ALENCASTRO, Luiz Felipe de (Org.). História da vida privada no Brasil 2. São Paulo: Companhia das Letras, 1997.

ALMEIDA, José Ricardo Pires de. História da instrução pública no Brasil (1500-1889). História e legislação. São Paulo: EDUC; Brasília: INEP/MEC, 1989.

ANDRADA E SILVA, José Bonifácio. Projetos para o Brasil (Organização de Miriam Dolhnikoff). São Paulo: Companhia das Letras, 1998.

ELIAS, Norbert. O processo civilizador, v. 2: formação do Estado e civilização. Rio de Janeiro: Zahar, 1993.

. Os alemães. Rio de Janeiro: Zahar, 1997.

.; SCOTSON, John. L. Os estabelecidos e os outsiders.

Rio de Janeiro: Zahar, 2000.

FONSECA, Marcus Vinicius. Pretos, pardos, crioulos e cabras nas escolas mineiras do século XIX. Tese (Doutorado em Educação) Faculdade de Educação, Universidade de São Paulo, São Paulo, 2007. 256 p.

GONÇALVES, Luiz Alberto Oliveira. Negros e educação no Brasil. In: LOPES, Eliane Maria Teixeira; FARIA FILHO, Luciano Mendes; VEIGA, Cynthia Greive (Orgs.). 500 anos de educação no Brasil. Belo Horizonte: Autêntica, 2000. p. 325-346.

GUTIÉRREZ, Horácio. Crioulos e africanos no Paraná, 1798-1830. Revista Brasileira de História, v. 8, n. 16, p. 161-188, mar./ago. 1988. HASENBALG, Carlos. Discriminação e desigualdades raciais no Brasil. Rio de Janeiro: Graal, 1979.

LARA, Silvia Hunold. Trabalhadores escravos. Trabalhadores. Campinas: Fundo de Assistência à Cultura, 1989.

LEITE, Ilka Boaventura. Antropologia de viagem. Belo Horizonte: Editora da UFMG, 1996.

MAESTRI, Mario. A pedagogia do medo: disciplina, aprendizado e trabalho na escravidão brasileira. In: STEPHANOU, Maria; BASTOS, Maria Helena Câmara (Orgs.). História e memórias da educação no Brasil. V. 1. Petrópolis: Vozes, 2004. p. 192-210. 
MARTINEZ, Alessandra Frota. Educar e instruir: a instrução popular na Corte imperial, 1841-1889. Dissertação (Mestrado em História) - Departamento de História, Universidade Federal Fluminense, Niterói, 1997. 300 p.

MATTOS, Hebe de Castro. Laços de família e direitos no final da escravidão. In: ALENCASTRO, Luiz Felipe de (Org.). História da vida privada no Brasil 2. São Paulo: Companhia das Letras, 1997. p. 337-385.

Das cores do silêncio: os significados da liberdade no Sudeste escravista, Brasil século XIX. Rio de Janeiro: Nova Fronteira, 1998.

Remanescentes das comunidades dos quilombos: memórias do cativeiro e políticas de reparação no Brasil. Revista USP, n. 68, p. 104-111, dez. 2005/fev. 2006.

MORAES, Christianni Cardoso. Ler e escrever: habilidades de escravos forros? Comarca do Rio das Mortes, Minas Gerais, 17311850. Revista Brasileira de Educação, v. 12, n. 36, p. 493-504, set./dez. 2007.

MOYSÉS, Sarita M. Affonso. Leitura e apropriação de textos por escravos e libertos no Brasil do século XIX. Educação \& Sociedade, n. 48, p. 200-213, ago. 1994.

MULLER, Maria Lucia. Professoras negras na Primeira República. Cadernos PENESB, Niterói: Intertexto, 1999.

MUSSA, Alberto Baeta Neves. O papel das línguas africanas na história do português do Brasil. Dissertação (Mestrado em Letras) - Faculdade de Letras, Universidade Federal do Rio de Janeiro, 1991. 242 p.

PAIVA, Eduardo França. Leituras (im)possíveis: negros e mestiços leitores na América Portuguesa. In: COLÓQUIO INTERNACIONAL POLÍTICA, NAÇÃO E EDIÇÃO, Belo Horizonte, 2003. Anais... Belo Horizonte: Programa de Pós-Graduação em História, Universidade Federal de Minas Gerais, 2003.

PRIORE, Mary del (Org.). História das crianças no Brasil. São Paulo: Contexto, 1999.

SCHWARCZ, Lilia Moritz. Nem preto nem branco, muito pelo contrário: cor e raça na intimidade. In: (Org.). His-

tória da vida privada 4. São Paulo: Companhia das Letras, 1998. p. $173-244$.

VEIGA, Cynthia Greive. Cidadania e educação na trama da cidade: a construção de Belo Horizonte em fins do século XIX. Bragança Paulista: EDUSF, 2002.

História social da infância: crianças pobres e não

brancas na institucionalização da instrução pública elementar em
Minas Gerais, século XIX. Relatório (Pesquisa de pós-doutoramento) - Departamento de História, Universidade de São Paulo, São Paulo, 2003.

. A produção da infância nas operações escriturísticas da administração da instrução elementar no século XIX. Revista Brasileira de História da Educação, n. 9, p. 73-108, jan./jun. 2005.

VILLALTA, Luiz Carlos. Reformismo ilustrado, censura e práticas de leitura: usos do livro na América portuguesa. Tese (Doutorado em História) - Departamento de História, Universidade de São Paulo, São Paulo, 1999. 553 p.

\section{Fontes documentais}

COLEÇÃO das Leis Mineiras, 1835-1890.

COLLEÇÃO das Leis do Império do Brazil de 1827. Rio de Janeiro: Typografia Nacional, 1878.

Correspondência referente à Inspeção de Ensino $1^{\mathrm{a}}$ à $4^{\mathrm{a}}$ circunscrições. Secretaria do Interior, 1899. SI 3958.

FALLA dirigida á Assembléa Legislativa Provincial na sessão ordinaria do anno de 1848 pelo presidente da província, Bernadino José de Queiroga. Ouro Preto: Typografia Social, 1848.

FALLA que o exm. Sr. Dr. Theophilo Ottoni dirigio á Assemblea Provincial de Minas Geraes, ao installar-se a 1.a sessão da 24.a legislatura em 1.o de agosto de 1882. Ouro Preto: Typ. de Carlos Andrade, 1882.

PRESIDÊNCIA da Província (PP) 1/42, caixa 01, envelope 07. PRESIDÊNCIA da Província (PP), caixa 08, pacotilha 09. PRESIDÊNCIA da Província (PP) 1/42, caixa 14, envelope 07. RELATORIO que ao ilustríssimo e excelentíssimo senhor Doutor José Ricardo de Sá Rego, presidente desta Província, apresentou o Vice-Diretor da Instrução Pública, Chantre Antonio José Ribeiro Bhering, em 1851. Ouro Preto: Typografia Social, 1852a.

RELATORIO que sobre o estado da Instrução Pública e particular da Província de Minas Geraes apresentou ao ilustríssimo e excelentíssimo senhor Doutor Luiz Antonio Barboza, muito digno Presidente da mesma província em 22 de fevereiro o vice-diretor geral, Chantre Antonio Jose Ribeiro Bhering. Ouro Preto, Typ. Do Bom Senso, 1852b.

RELATORIO que à Assemblea Legislativa Provincial de Minas Geraes apresentou no acto da abertura da Sessão ordinaria de 1862 o coronel Joaquim Camillo Teixeira da Motta, terceiro vice-presidente da mesma provincia. Ouro Preto: Typografia Provincial, 1862. 
RELATORIO que a Assembléa Legislativa Provincial de Minas Geraes apresentou na sessão ordinária de 1868 ao presidente da província José da Costa Machado de Souza. Ouro Preto: Typ. de J. F. de Paula Castro, 1868.

RELATORIO com que o exm. Sr. Senador Joaquim Floriano de Godoy no dia 15 de janeiro de 1873 passou a administração da Província de Minas Geraes ao segundo vice-presidente Exm. Sr. Dr. Francisco Leite da Costa Belém por ocasião de retira-se para tomar assento na Câmara Vitalícia. Ouro Preto, 1873.

RELATORIO que ao Ilm. e Exm. Sr. Dr. Francisco Leite da Costa Belém, segundo vice-presidente da Província de Minas Geraes, apresentou no ato de passar-lhe a administração da mesma província o exm. Sr. Desembargador João Antonio de Araújo Freitas Henriques, a 6 de março de 1875. Ouro Preto: Typ. de J. F. de Paula Castro, 1875.

RELATORIO apresentado á Assemblea Legislativa Provincial de Minas Geraes na sessão ordinária de 1876 pelo presidente da mesma província Barão da Villa da Barra. Ouro Preto: Typ. de J. F. de Paula Castro, 1876.

RELATÓRIO que apresentou ao Exmo. Sr. Vice-Presidente da Província de Minas Gerais Dr. Elias Pinto de Carvalho por ocasião de lhe passar a administração de 30 de juho de 1867, o conselheiro Joaquim Saldanha Marinho presidente da mesma província. Rio de Janeiro: Typographia Perseverança, rua do Hospicio, n. 91, 1867.

RELATORIO que á Assembléa Legislativa Provincial de Minas Geraes apresentou o exm. Sr. Senador João Florentino Meira de Vasconcellos, por ocasião de ser installada a mesma Assembléa para a segunda sessão ordinária de 23.a legislatura em 7 de agosto de 1881. Ouro Preto: Typ. da Actualidade, 1881.

SEÇÃO Provincial, Instrução Pública 1/1, caixa 58, pacotilha 18. SEÇÃO Provincial, Instrução Pública 1/42, caixa 05, pacotilha 60. SEÇÃO Provincial, Instrução Pública 3/2, caixa 01, pacotilhas 05 e 17 SEÇÃO Provincial, Códice 235.

REVISTA DO ARQUIVO PÚBLICO MINEIRO, ano IX, p. 236, jan./ jun. 1904.

REVISTA DO ENSINO, ano IX, n. 198, p. 23, jan./mar. 1951.

VIDA ESCOLAR, boletim quinzenal do Grupo Escolar de Lavras, Lavras, Estado de Minas Gerais, 15 jun. 1908.

CYNTHIA GREIVE VEIGA, doutora em história pela Universidade Estadual de Campinas (UNICAMP), é professora da Faculdade de Educação da Universidade Federal de Minas Gerais (UFMG) e bolsista de produtividade de pesquisa do Conselho Nacional de Desenvolvimento Científico e Tecnológico (CNPq). Publicações recentes: Infância no sótão (Belo Horizonte: Autêntica, 1999); História da educação (São Paulo: Ática, 2007); com FONSECA, Thais Nivia de Lima, organizou História e historiografia da educação no Brasil (Belo Horizonte: Autêntica, 2003). Pesquisa atual: "A docência na escola primária: relações de geração, gênero, classe social e etnia (Minas Gerais, séculos XIX e XX)”. E-mail: greive@fae.ufmg.br

Recebido em fevereiro de 2008 Aprovado em junho de 2008 
Margarida Louro Felgueiras

\section{A história da educação na relação com os saberes histórico e pedagógico}

Na historiografia da história da educação, vários autores têm salientado a posição "entre-dois" que a disciplina ocupa (Nóvoa, 1994, p. 21; Depaepe, 1993, p. 31). Disciplina histórica, elemento estruturante da incipiente ciência da educação, só se desenvolveu historicamente no campo institucional da formação de professores, a que ficou vinculada. A partir dessa situação, propomo-nos analisar a questão de forma semi-retrospectiva, evocando recordações da experiência pessoal. A partir delas, caminhamos na interrogação ao passado, tomando Portugal por campo de observação, ao mesmo tempo em que lançamos um olhar sobre a situação da história da educação em outros países europeus. Pretendemos problematizar o lugar da história da educação no sistema de ensino, compreender como se sedimentou a história da educação na área da formação dos docentes e que papel aí representou. Da sistematização de algumas questões em torno dessa problemática pretendemos discutir o carácter híbrido da história da educação, com as dificuldades e oportunidades daí decorrentes.

Palavras-chave: história da educação; saber pedagógico; formação de professores; ensino da história da educação

\section{The history of education in relation to historical and pedagogical knowledge}

In the historiography of the history of education, different authors have emphasized the "in-between" position which the discipline occupies (Nóvoa, 1994, p. 21; Depaepe, 1993, p. 31). The discipline, a structuring element in the incipient science of education, developed historically only in the institutional field of the training of teachers, to which it became linked. Based on this situation, we propose to analyze the question in a semiretrospective manner, evoking memories of personal experience. Based on these, we shall interrogate the past, taking Portugal as our field of observation whilst at the same time taking a look at the situation of the history of education in other European countries. We intend to problematize the place of the history of education in the field of teacher training and the role which it represents there. Starting with a systematization of some questions related to this theme, we intend to discuss the hybrid nature of the history of education, with the difficulties and opportunities inherent in it.

Key words: history of education; pedagogical knowledge; teacher training; teaching of the history of education

La historia de la educación en la relación con los saberes histórico y pedagógico

En la historiografía de la historia de la educación, varios autores han resaltado la posición "entre dos" que la diciplina ocupa (Nóvoa, 1994, p. 21; Depaepe, 1993, p. 31). Diciplina histórica, elemento estructural de la incipiente ciencia de la educación, sólo se desarrolla históricamente en el campo institucional de la formación de profesores, a la que quedó vinculada. A partir de esa situación nos proponemos analizar la cuestión de forma semi retrospectiva, evocando recordaciones de la experiencia personal. A partir de ellas, caminamos en la interrogación al pasado, tomando Portugal por campo de observación, al mismo tiempo que lanzamos una ojeada sobre la situación de la historia de la educación en otros países europeos. Pretendemos problematizar el lugar de la historia de la educación en el sistema de enseñanza, comprender como se sedimentó la historia de la educación en el área de la formación de los docentes y que papel ahí representó. De la sistematización de algunas cuestiones en vuelta de esa problemática, pretendemos discutir el carácter híbrido de la historia de la educación, con las dificultades y oportunidades de ahí transcurridas.

Palabras clave: historia de la educación; saber pedagógico, formación de profesores; enseñanza de la historia de la educación

Cynthia Greive Veiga

Escola pública para os negros e os pobres no Brasil: uma invenção imperial

$\mathrm{O}$ artigo apresenta dados finais de pesquisa sobre a escolarização de crianças pobres, negras e mestiças no Brasil, especificamente na província de Minas Gerais, durante a vigência da Monarquia constitucional (1824-1889). Para seu desenvolvimento, foram investigados diferentes documentos da instrução pública; a principal tese é demonstrar o caráter popular da escola do Império e discutir que o seu fracasso na função de instruir e civilizar pobres, negros e mestiços pode estar exatamente relacionada à desqualificação da condição de educabilidade da clientela à qual se destinava a escola pública do século XIX. Destaca ainda a importância da temática para ampliação dos debates sobre a história da escola no Brasil.

Palavras-chave: história da educação; educação imperial; escola pública; classe social; etnia

Public schools for negroes and the poor in Brazil: an imperial invention This paper presents the final research data on the schooling of poor, negro and mixed-race children in Brazil, particularly in the province of Minas Gerais during the constitutionalist Monarchy (1824-1889). The main 
objective of this dissertation which analysed diverse documents on public education is to demonstrate the popular character of the school in the Empire and argument that its failure in the function of educating and civilizing poor, negro and mixed-race children is exactly in the characterization of the clientele at whom the public school was aimed in the XIX century as non-educable. The importance of the theme for deepening the debate on the history of the school in Brazil is also highlighted.

Key words: history of education; imperial education; public school; social class; race

Escuela pública para los negros y los pobres en Brasil: un invento imperial El artículo presenta datos finales de estudios sobre la escolarización de niños pobres, negros y mestizos en Brasil, específicamente en la provincia de Minas Gerais durante la vigencia de la Monarquía constitucional (18241889). Para su desarrollo fueron investigados diferentes documentos de la instrucción pública y la principal tesis es demostrar el carácter popular de la escuela del Imperio y discutir sobre como su fracaso en la función de instruir y civilizar pobres, negros y mestizos puede estar exactamente relacionada con la descalificación de la condición de educabilidad de la clientela a la cual se destinaba la escuela pública del siglo XIX. Destaca también la importancia de la temática para la ampliación de los debates sobre la historia de la escuela en Brasil.

Palabras clave: historia de la educación; educación imperial; escuela pública; clase social; etnia

Petrônio Domingues

\section{Um “templo de luz": Frente Negra Brasileira (1931-1937) e a questão da educação \\ $\mathrm{O}$ artigo examina como a Frente Negra}

Brasileira (1931-1937) - considerada a maior e mais importante organização negra que se projetou no cenário nacional após a abolição da escravatura - discutiu, problematizou e tratou a questão da educação. Verifica-se como as lideranças dessa organização tinham uma visão crítica em relação à falta de políticas públicas voltadas à população negra e concebiam a educação como uma ferramenta estratégica para a inserção desse segmento populacional à sociedade. Além da integração social, a educação possibilitaria a eliminação dos preconceitos e, em última instância, garantiria as condições para o exercício da cidadania plena.

Palavras-chave: negros; relações raciais; educação; multiculturalismo

\section{A "temple of light": the Brazilian} Negro Front (Frente Negra Brasileira) (1931-1937) and the education question

The article analyses how the Brazilian Negro Front (1931-1937) - considered the largest and most important black organization to be projected on the national scene after the abolition of slavery-discussed, questioned and dealt with the issue of education. It can be observed that the leaders of that organization had a critical vision of the lack of public policies for the black population and saw education as a strategic tool for the social integration of this segment of the population. In addition to social integration, education would make possible the elimination of prejudice and, ultimately, would ensure the conditions for the exercise of full citizenship.

Key words: negroes; race relations; education; multiculturalism

\section{Un “templo de luz": Frente Negra Brasileña (1931- 1937) y la cuestión de la educación \\ El artículo examina como la Frente Negra Brasileña (1931-1937) - considerada la mayor y la más}

importante organización negra que se ha proyectado en el escenario nacional después de la abolición de la esclavitud - discutió, problematizó y trató la cuestión de la educación. Se comprueba como las lideranzas de esa organización tenían una visión crítica en relación a la falta de políticas públicas destinadas a la populación negra y concebían la educación como una herramienta estratégica para la inserción de ese segmento popular a la sociedad. Además de la integración social, la educación posibilitaría la eliminación de los perjuicios y, en última instancia, garantiría las condiciones para el ejercicio da la plena ciudadanía.

Palabras clave: negros; relaciones raciales, educación; multiculturalismo

Thais Nivia de Lima e Fonseca

Instrução e assistência na capitania de Minas Gerais: das ações das câmaras às escolas para meninos pobres (1750-1814)

Neste artigo, pretende-se discutir as relações entre a função civilizadora da instrução e de seu papel assistencial pelo estudo das ações das câmaras e de instituições pias para a educação de meninos pobres. No Antigo Regime, a educação para as camadas mais baixas da população associava-se à difusão da doutrina cristã e à formação profissional como meios de controle e era realizada em instituições assistencialistas. O ensino das primeiras letras visava facilitar o aprendizado da doutrina, sem criar possibilidades de ascensão social pela educação. Sobressaía a solução da educação profissional, do aprendizado de ofícios que pudessem servir de ocupação e de sustento. A legislação portuguesa definia os destinos a serem dados aos órfãos, e a educação que lhes seria destinada deveria ser compatível com seu nível social de origem. Na América 